\title{
Rheotanytarsus dactylophoreus, a new mountain species from streams in the Eastern Pyrenees and Corsica (Diptera: Chironomidae)
}

\author{
Joel Moubayed-Breil', Peter H. Langton² and Patrick Ashe ${ }^{3}$
}

\begin{abstract}
Moubayed-Breil J, Langton PH and Ashe P. 2012. Rheotanytarsus dactylophoreus, a new mountain species from streams in the Eastern Pyrenees and Corsica (Diptera: Chironomidae). Fauna norvegica 31: 167-173.

The description of Rheotanytarsus dactylophoreus sp. nov. is based on adult males, pharate males and pupal exuviae collected in low and middle mountain streams located in the Eastern Pyrenees and Corsica is presented. The most distinctive character in the adult male is the unusually long, fingerlike, digitus and in the pupal exuviae is the thoracic horn which is spinulate laterally (extending from swollen base into tapered apical half). The distribution of $R$. dactylophoreus sp. nov. indicates that this pyreneocorsican species is a Tyrrhenian faunal element which spread westwards to mountain streams of the Eastern Pyrenees perhaps during the repeated waves of migration from the Paleocene (Montian) till the late Miocene.
\end{abstract}

doi: 10.5324/fn.v31i0.1375. Received: 2011-10-14. Accepted: 2012-07-11.

Published on paper and online: 2012-10-17.

Keywords: Chironomidae, Rheotanytarsus, new species, Tyrrhenian element, Corsica, Eastern Pyrenees

1. Applied ecology and biodiversity, 10 rue des Fenouils, F-34070 Montpellier, France

2. 16 Irish Society Court, Coleraine, Co. Londonderry, BT52 1GX Northern Ireland

3. 33 Shelton Drive, Terenure, Dublin 12, Ireland

Corresponding author: Joel Moubayed-Breil

E-mail:jm.aquabiol@neuf.fr

\section{INTRODUCTION}

In the genus Rheotanytarsus Thienemann \& Bause, 1913 a total of 94 valid species worldwide were listed by Sæther \& Kyerematen (2001) but since then some additional species have been described or recognised. The genus is recorded from all zoogeographical regions except Oceania and Antarctica. There are several reviews published which include keys to species in different regions (e.g. Fittkau 1960; Lehmann 1970; Shilova 1976; Lehmann 1981; Cloutier \& Harper 1986; Moubayed 1990; Wang \& Zheng 1993; Chaudhuri et al. 1994; Langton \& Armitage 1995; Cranston 1997; Kyerematen \& Sæther 2000; Kyerematen et al. 2000 a; Kyerematen et al. 2000 b; Andersen \& Kyerematen 2001; Kyerematen \& Andersen 2002; Burmeister \& Reiss 2003; Wang \& Guo 2004; Giłka 2011). As a result of these reviews the fauna of several zoogeographical regions, including the Palaearctic, Afrotropical, Oriental, Australasian and Neotropical, is quite well known. In the Nearctic at least seven species are known but there is no comprehensive review of the fauna available. A phylogenetic and zoogeographical analysis of the genus has been published by Sæther \& Kyerematen (2001).

A revision of the European species by Lehmann (1970) comprises eight species. Including $R$. dactylophoreus sp. nov., the number of Rheotanytarsus species rises to 16 in the western Palaearctic (Europe, North Africa and the Near East). There were nine species reported from France (nine from continental France and six from Corsica) (Sæther \& Spies 2011) prior to the description here of $R$. dactylophoreus sp. nov.

The description of the adult male and pupal exuviae of $R$ dactylophoreus is based on material collected in France (Eastern Pyrenees and Corsica). Adults, pharate adults and pupal exuviae of $R$. dactylophoreus are reported from the Pyrenees by Moubayed et al. (2000) and Moubayed-Breil (2007) as Rheotanytarsus sp. 1 whereas only pupal exuviae of $R$. dactylophoreus, have been recorded from Corsica by Laville 
\& Langton (2002) as Rheotanytarsus sp. A and by Langton \& Visser (2003) as Rheotanytarsus Pe4.

\section{MATERIAL AND METHODS}

The adult specimens were cleared in $90 \%$ lactic acid which took a minimum of 20-30 minutes, but could be left overnight at room temperature without any detrimental effect or damage. When clearing was complete the specimens were washed in two changes of $70 \%$ ethanol to ensure that all traces of lactic acid were removed. All examined material (adults and pupal exuviae) was mounted in polyvinyl lactophenol. Before the final slide preparation was made the hypopygium was viewed laterally (to draw a side view of the anal point) and ventrally to examine or draw the median volsella before the hypopygium was turned into its permanent dorsal position and covered with a coverslip. Several adult specimens were available and the eye on one side was dissected from the head to ensure that the microtrichia on the inner margin of eye were more clearly visible.

Terminology follows that of Sæther (1980) and Langton \& Pinder (2007) for the adult male, and Sæther (1980) and Langton (1991) for the pupal exuviae. Keys to separate adult males and pupal exuviae of $R$. dactylophoreus from other related known species in the western Palaearctic are provided.

\section{RESULTS}

\section{Rheotanytarsus dactylophoreus sp. nov. \\ (Figures 1, 7-20) \\ Rheotanytarsus sp. A (from Corsica): Laville \& Langton (2002).}

Rheotanytarsus Pe4 (from Corsica): Langton \& Visser (2003)

Rheotanytarsus sp. 1 (from continental France): Moubayed et al. (2000), Moubayed-Breil (2007).

\section{Type material}

Holotype: FRANCE: Eastern Pyrenees, natural reserve of Py, Campeilles stream, a tributary of the Rotja River, altitude 1300$1400 \mathrm{~m}, 21 . v i .2005$ (1 pharate male).

Paratypes: FRANCE: Eastern Pyrenees, Tech River, 11.vii.2000 (1 male adult); same locality, 10.vi.2003 (1 male adult); same locality, 9.vii.2001 (1 pharate male); same locality, 8.vi.2000 (4 males and 3 pharate females); Campeilles and Cantallops streams, 22.vii.2003 (1 pharate male, 2 male and 3 female pupal exuviae,); Nohèdes River, 12.vii.1996 (1 male and 1 female pupal exuviae); Massane River, 21.vi.1986 (1 male pupal exuviae); FRANCE: Corsica, Fango River, 4.vii.1997 (1 male and 1 female pupal exuviae); Restonica River, 5.vii.1997 (1 male pupal exuviae). The pupal exuviae from the Fango River (Corsica) were collected by E. Morello; all other material including the holotype and remaining paratypes were collected by J. Moubayed-Breil.
Holotype and 3 paratypes (1 pharate male and 2 female pupal exuviae) are deposited in the collection of the National Museum of Ireland, Kildare Street, Dublin 2, Ireland. Remaining paratypes are deposited in the collection of J. Moubayed-Breil.

\section{Etymology}

The new species is named after the distinctive, finger-like, shape of the digitus (from the Greek: dactylos meaning finger and phoreos meaning bearer) in the male hypopygium.

\section{Diagnosis}

Adult male: AR 0.51-0.55. Eye with microtrichia on dorsal and lateral inner margin. Caudal margin of tergite IX narrowed distally; anal point uniformly tapered distally, bearing 12-14 setae basally, 6-7 on each side; finger-like digitus extends beyond margin of superior volsella; posterior margin of superior volsella knob-like; median volsella not reaching the apex of the inferior volsella; setiferous ventral lobe of the inferior volsella bearing 2 stout setae. Tip of gonostylus abruptly tapering to a minute apical prominence.

Pupa: Cephalic tubercles hardly distinct to projecting, broad, each bearing a bristle-like frontal seta; thoracic horn swollen at base with apical half uniformly narrowing, bearing 16-19 setulae in one row, which are confined to the proximal half to near the base; tergites II-VI each with a pair of point patches; tergite II-III with transversely elongate point patches becoming subrectangular to subcircular on tergites IV-VI; shagreen on tergite II consists of a single lateral band of points; tergites III-VI with larger and more dense shagreen; spur on segment VIII with a few accessory minute spines; dorsal setae on anal segment bristle-like; fringe with 11-13 taeniae (male), 12-14 (female).

\section{Description}

The description of $R$. dactylophoreus is based on both male and female pharates and pupal exuviae collected in middle to low mountain streams and rivers in the Eastern Pyrenees and Corsica.

\section{Adult male $(\mathrm{n}=3)$ (Figures 1, 7-12)}

Total length $2.60-2.95 \mathrm{~mm}$. Antenna length $0.985-1.060 \mathrm{~mm}$. Wing length 1.80-1.85 mm. Abdomen length 0.995-1.010 mm. Colour: Cephalothorax greenish yellow to brownish. Anal point darkened, crests distinctly blackish. Legs pale yellow to brown with apex of tibia and tarsus 1 of $p_{2}$ and $p_{3}$ darkened; spurs on tibia of $p_{2}$ and $p_{3}$ dark. Abdomen greenish to brownish. Anal point crests dark.

Head. AR 0.51-0.55. Eyes bare between ommatidia; microtrichia present on dorsal and lateral inner eye margin (Figure 1). Temporal setae 9-10 including 5-6 inner, 2 outer orbitals and 2 postorbitals. Antenna (Figure 7) with 2 apical setae $65-70 \mu \mathrm{m}$ long; last flagellomeres 350-360 $\mu \mathrm{m}$ long. Clypeus with 30-36 setae. Palpomere lengths (in $\mu \mathrm{m}$ ): 35-40, 70-75, 90-95, 105-110, 165-170. 
Thorax chaetotaxy. Aps 6-8, Ac 16, Dc 8 in row, Pa 3-4, Scts 6-7 in row.

Wing. Membrane densely pubescent. All veins hairy (except M), number of setae: $\mathrm{R}, 32-34 ; \mathrm{R}_{1}, 48 ; \mathrm{R}_{4+5}, 75-80 ; \mathrm{M}$ bare; $\mathrm{Cu}$, 24; $\mathrm{Cu}_{1}, 26 ; \mathrm{PCu}, 34 ; \mathrm{An}, 44$; all cells hairy. Squama bare.

Legs. Apex of fore tibia with a peg-like spur; pair of apical combs on mid and hind tibia straight; spur of mid tibia a little longer than comb setae; spur of hind tibia twice as long as the length of the comb setae.

Length (in $\mu \mathrm{m}$ ) and proportions of legs:

\begin{tabular}{ccccccc}
\hline & $\mathrm{fe}$ & $\mathrm{ti}$ & $\mathrm{ta}_{1}$ & $\mathrm{ta}_{2}$ & $\mathrm{ta}_{3}$ & $\mathrm{ta}_{4}$ \\
\hline $\mathrm{p}_{1}$ & 945 & 650 & 960 & 530 & 380 & 320 \\
$\mathrm{p}_{2}$ & 920 & 720 & 430 & 240 & 190 & 120 \\
$\mathrm{p}_{3}$ & 1045 & 925 & 650 & 395 & 320 & 190 \\
\hline & $\mathrm{ta}_{5}$ & $\mathrm{LR}$ & $\mathrm{BV}$ & $\mathrm{SV}$ & $\mathrm{BR}$ \\
\hline $\mathrm{p}_{1}$ & 150 & 1,0 & 1.85 & 1.66 & 1.7 \\
$\mathrm{p}_{2}$ & 108 & 0.47 & 3.15 & 3.81 & 3.6 \\
$\mathrm{p}_{3}$ & 125 & 0.62 & 2.54 & 3.03 & 1.9 \\
\hline
\end{tabular}

Hypopygium (Figures 8-12). Dorsal and partial ventral view as shown in Figure 8a. Anal tergite bands dark V-shaped, well separated basally but narrowing apically, almost reaching crests; caudal margin of tergite IX gradually narrowed toward base of anal point. Anal point darkened, 80-85 $\mu \mathrm{m}$ long, almost parallel-sided at base, uniformly elongated and slightly narrowed at tip; maximum width 22-24 $\mu \mathrm{m} ; 12-14$ setae present basally, 6 to 7 on each side of the anal point; crests V-shaped, separated basally, closed distally, with 5-7 setae inserted between anal tergite bands. In lateral view (Figure 9), anal point crests broad, distinctly blackish, well developed. Laterosternite IX with 5-6 setae. Phallapodeme 80-90 $\mu \mathrm{m}$ long; transverse sternapodeme 45-50 $\mu \mathrm{m}$ long. Superior volsella (Figure 10) 40-45 $\mu \mathrm{m}$ long, maximum width 22-26 $\mu \mathrm{m}$; oblong to almost knob-like with a slightly pointed inner apex, bearing 7 minute dorsal setae and 2 lateroventral setae directed inwards; in ventral view, one stout seta on inner basal margin of digitus (Figure 10). Median volsella (Figure 8a, dorsal view, Figure 11, ventral view) slightly curved downwards, about 60-65 $\mu \mathrm{m}$ long, not reaching tip of inferior volsella; bearing short to medium sized setae at base and much longer setae medially; apically with 4 spatulate lamellae without apical points. Inferior volsella (Figures. 8a, 8b) 85-90 $\mu \mathrm{m}$ long, 20-22 $\mu \mathrm{m}$ wide, swollen basally, bent inwards medially, densely covered with microtrichia; bearing about 10 stout curved setae on dorsal side (Figure 8a) and indistinct setiferous ventral lobe bearing 2 stout setae (37-40 $\mu \mathrm{m}$ long) ventrally (Figure 8b). Gonocoxite 95-105 $\mu \mathrm{m}$ long; basal margin broad, swollen at base and covered with microtrichia, inner margin with 5 long and stout setae. Gonostylus 115-120 $\mu \mathrm{m}$ long, parallel-sided, tip abruptly tapering to a minute apical prominence (Figure 12).
Adult female: Known but not described.

Pupal exuviae $(n=11)$ (Figures 13-20)

Total length 2.65-3.0 mm. Cephalothorax dark, darker dorsomedially and around the base of the thoracic horn. Wing sheaths with dark shading on basal half and dark bands present longitudinally. Abdomen and anal segment brown to dark; segment I-VI brownish, darker laterally. Anal segment dark, with colourless band medially; genital sac transparent.

Cephalothorax (Figures 13-14). Frontal apotome (Figure 13) smooth not granulated, with indistinct to distinct broad tubercles; frontal setae 70-80 $\mu \mathrm{m}$ long, bristle-like. Antepronotals 91 and $35 \mu \mathrm{m}$ long. Dorsocentrals bristle-like; Dc1-Dc4: 15, 51, 30, 40 $\mu \mathrm{m}$ long respectively. Thoracic horn (Figure 14) 205-215 $\mu \mathrm{m}$ long, transparent, strongly swollen in proximal half, abruptly thin and uniformly narrowing in distal half, flat in proximal half and twisting in distal half; bearing 16-19 setulae on
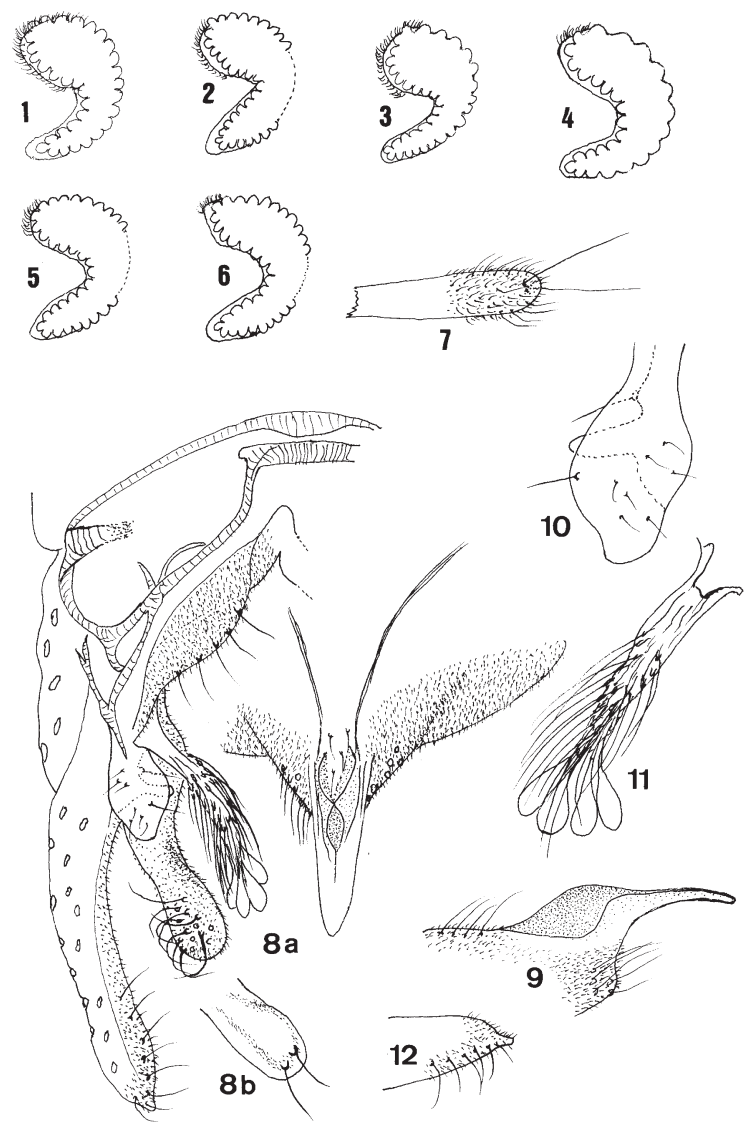

Figures I-I2. Rheotanytarsus spp., adult: (1-5) Microtrichia on dorsal and lateral inner margin of eye: (1) $R$. dactylophoreus sp. nov.; (2) $R$. ringei Lehmann; (3) $R$. sp.1, Lebanon, near reissi; (4) $R$. pentapoda Kieffer; (5) $R$. rhenanus Klink; (6) R. samaki Lehmann. $R$. dactylophoreus sp. nov., adult male (7-12): (7) apex of antenna, (8a) hypopygium, dorsal and partial ventral view; tip of inferior volsella in ventral view (8b); (9) anal point in lateral view; (10) superior volsella; (11) median volsella; ventral view (12) apex of gonostylus in lateral view. 


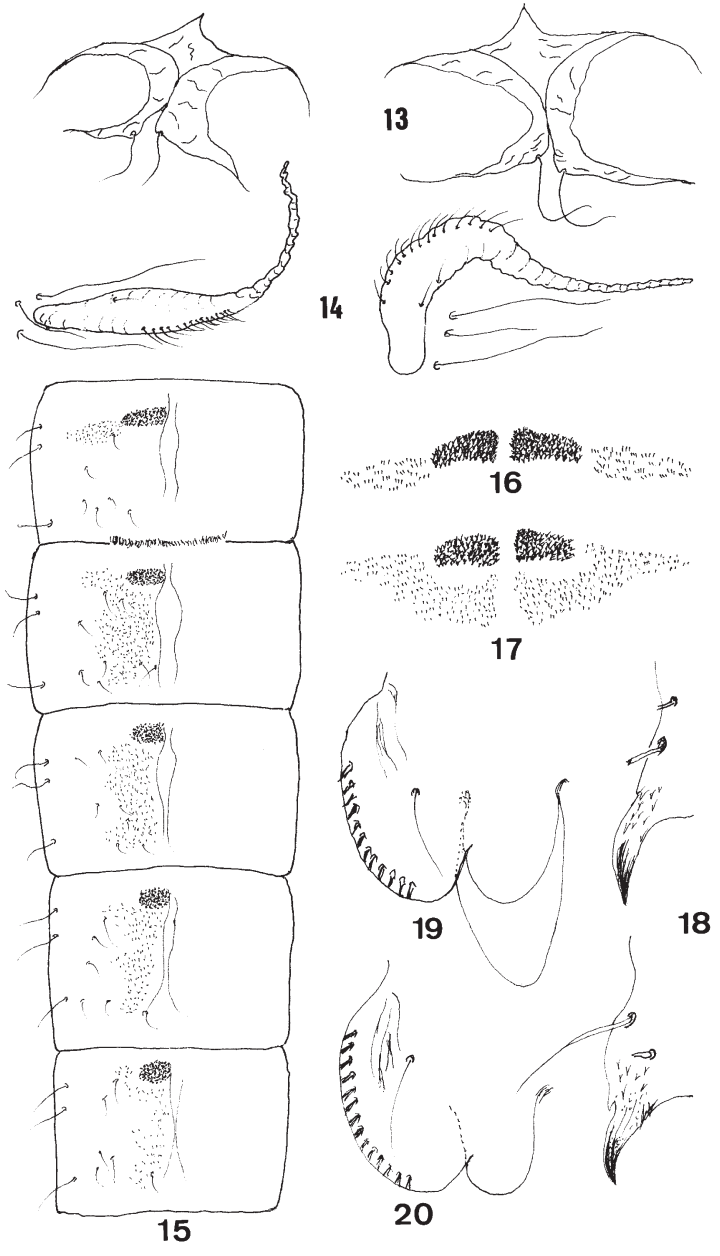

Figures 13-20. Rheotanytarsus dactylophoreus sp. nov., pupal exuviae:

(13) Frontal apotome, two aspects; (14) thoracic horn, two aspects;

(15) armament of abdominal segments II-VI; $(16,17)$ pattern shape of point patches and shagreen on tergites II (16) and III (17); (18) caudolateral spur of segment VIII, two aspects; $(19,20)$ anal segment, left side, of male (19) and female (20).

proximal half, about 18 spinulae laterally in one row and $0-2$ spinulae basally. Precorneal setae 150-175, 60-75 and 70-95 $\mu \mathrm{m}$ long. Thorax with faint granulations near the suture and in the median area.

Abdomen (Figures 15-20). Tergites II-VI (Figure 15) each with a pair of point patches; tergite II (Figure 16) with 45-55 hooks in transverse hook row; point patches transversely elongated on tergites II-III (Figures 16-17), becoming subrectangular to subcircular on IV-VI; tergite II with a lateral band of points; tergites III-VI with a larger area of shagreen which is more extensive on tergites III and IV. Lateral setae on segments IVIII: 0, 2-3, 3, 3, 3, 3, 3, 4. Caudolateral spur on segment VIII dark, with a few accessory minute spines dorsally (Figure 18). Dorsal bristle-like setae on anal segment, 55-65 $\mu \mathrm{m}$ long; fringe with 11-13 taeniae in male (Figure 19), 12-14 in female (Figure 20). Anal segment 175-180 $\mu \mathrm{m}$ long, maximum width 210-215 $\mu \mathrm{m}$. Genital sac of male 180-185 $\mu \mathrm{m}$ long, overreaching tip of anal segment by $85-90 \mu \mathrm{m}$ (Figure 19); genital sac of female 65$70 \mu \mathrm{m}$ long, reaching tip of anal segment (Figure 20).

Larva: Known but not described.

\section{DISCUSSION}

A world wide revision of the genus Rheotanytarsus has been provided by Kyerematen et al (2000 a, 2000 b), Sæther \& Kyerematen (2001), Kyerematen \& Sæther (2000), Kyerematen \& Andersen (2002) including a "composition of tentative groups" based on characters of both adult males and pupal exuviae. The guineensis group represents one of these (Sæther \& Kyerematen 2001), which consists of 17 species occurring in all zoogeographical regions that the genus is known from.

In general, all members of this group have in common the following combination of characters. In the adult male: the superior volsella is not rounded and its posterior margin is hooklike to knob-like; digitus often present (when present either not reaching or sometimes extending beyond margin of superior volsella); median volsella often S-shaped (sometimes strongly or weakly curved, rarely straight), not reaching the apex of the inferior volsella, apically variable (with either flattened plates, setiform or spatulate lamellae), with or without points. In the pupal exuviae: the thoracic horn is spinulate apically or bare; the point patches on tergites II-III are rectangular or transversely elongate instead of rounded; anal lobe with or without hair-like seta.

On the basis of all the above cited characters $R$. dactylophoreus keys directly into the guineensis group. On the basis of the blackish colour of the crests and the shape of the anal point in dorsal and lateral view $R$. dactylophoreus is similar to R. nigricauda Fittkau, 1960; on the shape of the superior volsella it resembles $R$. guineensis Kieffer, 1918, $R$. rhenanus Klink, 1983 and $R$. rioensis Langton \& Armitage, 1995 and on pupal exuviae characters resembles $R$. guineensis, $R$. ringei Lehmann, 1970, $R$. nigricauda, $R$. rhenanus and $R$. procerus).

In $R$. dactylophoreus, the main differentiating characters in the male are: caudal margin of tergite IX narrowed distally; presence of a digitus extending beyond margin of the superior volsella; median volsella not reaching apex of the inferior volsella and bearing spatulate lamellae distally; in the pupal exuviae: presence of cephalic tubercles and frontal setae, pattern of setulae on the thoracic horn, pattern of armament and shagreen on tergites II-VI, presence of dorsal setae on the anal lobe, fringe with 11-14 taeniae.

The presence of microtrichia on the apical and lateral inner margin of the eyes has not previously been reported or observed in the genus Rheotanytarsus but is illustrated here for six species (Figures 1-6). This feature may prove to be a useful additional feature for separating different species from 
one another but more intra and inter specific investigation is required than is possible in this paper. The microtrichia on the margins of the eyes become more clearly visible when the eye is separated from the head.

The species $R$. dactylophoreus is keyed below in the adult male with reference to related known species from Europe, the Near East and North Africa based on associated pharate specimens (which in the pupal exuviae are characterised by bearing five pairs of point patches on the tergites); i.e. $R$. rhenanus, $R$. reissi, $R$. pentapoda, $R$. nigricauda, $R$. ringei, $R$. rioensis and $R$. procerus. In addition, the key includes variable pupal features which are useful for identification, such as: the presence or absence of frontal setae; shape of frontal tubercles; dorsal setae on the anal lobe and the number of setae on the fringe. This key recognises the re-establishment of $R$. distinctissimus (Brundin, 1947) as a valid species by Stur \& Ekrem (pers. comm. at the $18^{\text {th }}$ Inter. Symp. on Chironomidae in Trondheim) who removed it from synonymy with the North American R. pellucidus (Walker, 1848).

\section{Key to separate $R$. dactylophoreus sp. nov. from known West Palaearctic Rheotanytarsus \\ Male adult}

1 Median volsella extremely long, with lamellae reaching the end of the gonostylus R. distinctissimus

- Median volsella much shorter 2

2 Median volsella with flattened plates distally, stem usually S-shaped or strongly curved, rarely straight or slightly curved

several species [including: R. curtistylus Goetghebuer, 1921, R. illiesi Siebert, 1979, R. muscicola Thienemann, 1929, R. pentapoda Kieffer, 1909, R. photophilus Goetghebuer, 1921, R. procerus Reiss, 1991, $R$. reissi Lehmann, 1970, $R$. rhenanus, $R$. ringei, $R$. rioensis]

- Median volsella with distal setiform or spatulate lamellae, stem not S-shaped, either straight or slightly curved downwards ... 3

3 Median volsella exclusively composed of setiform lamellae distally (Lehmann 1970, Figure 16); Inferior volsella ventrally lacking a lobe and stout setae (Lehmann 1970, Figure 15); Digitus may or may not extend beyond inner margin of superior volsella; Gonostylus (in lateral view) lacking a minute prominence apically (Lehmann 1970, Figure 15)

\section{R. nigricauda}

Median volsella with spatulate lamellae distally (Figure 11); Inferior volsella ventrally bearing a setiferous ventral lobe with 2 stout setae (Figure 8b); Digitus extending beyond inner margin of superior volsella (Figures 8a, 10); Gonostylus (in lateral view) bearing a minute prominence apically (Figure 12) $R$. dactylophoreus sp. nov.

\section{Pupal exuviae}

(This key includes species bearing 5 pairs of spine patches on tergites II-VI)

1 Anal lobe with one dorsolateral seta .................................. 2

- Anal lobe without dorsolateral seta .................................... 5

2 Thoracic horn entirely bare, uniformly tapering from base to apex ... 3

Thoracic horn spinulate, moderately constricted medially

4

3 Frontal tubercles and frontal setae absent; Fringe of anal lobe with 28-36 setae rioensis

- Frontal tubercles and frontal setae present; Fringe of anal lobe with 13-16 setae ... nigricauda

4 Thoracic horn spinulate laterally (extending from swollen base into tapered apical half); Fringe of anal lobe with 1114 setae dactylophoreus sp. nov.

- Thoracic horn spinulate only in tapered apical half; Fringe of anal lobe with 21-23 setae reissi

5 Thoracic horn bare, transparent, swollen basally, abruptly constructed medially; Frontal setae and frontal tubercles absent ringei Thoracic horn strongly to moderately spinulate apically, not transparent, usually tapering gradually; Frontal setae and frontal tubercles present ... 6

6 Thoracic horn abruptly bent at mid-length, constricted medially and strongly spinulate distally; Pairs of points patches rounded on tergites II-VI pentapoda

- Thoracic horn not abruptly bent at mid-length, evenly tapering towards apex and moderately spinulate distally; Pairs of points patches variable on tergites II-VI ............. 7

7 Pairs of points patches on tergites II-III moderately elongated transversally, becoming subrectangular to subcircular on tergites IV-VI rhenanus

- Pairs of points patches on tergites II-III rectangular, becoming circular on tergites IV-VI procerus

\section{Ecology and geographical distribution}

Rheotanytarsus dactylophoreus is a sparsely distributed species known from and confined to very few low to middle mountain streams located in the Eastern Pyrenees and Corsica (altitude mostly 600-1200 m a.s.l.). These include six streams in the Eastern Pyrenees (Tech, Mantet, Campeilles, Cantallops, Massane and Nohèdes) and seven streams in Corsica (Fango, Vecchio, Fiumicicoli, Restonica, Solenzara, Golo and Tavignano). In sections of two streams, exposed to Mediterranean climatic influence, some populations of $R$. dactylophoreus are recorded at higher altitudes, in the Mantet and Tech at $1200-1400 \mathrm{~m}$. At least six of the 12 prospected 
streams are fortunately protected because they are located within the boundaries of several nature reserves located in both the Eastern Pyrenees (Mantet, Massane, Nohèdes, Py and Prats-De-Mollo) and Corsica (Fango).

The species $R$. dactylophoreus is currently restricted to two areas of France (the Eastern Pyrenees and Corsica) in the western Mediterranean region. Species described from these areas often prove to be more widespread in the Tyrrhenian subregion which includes, according to Furon $(1950,1972)$ and Jeannel (1956), the Italian Peninsula and the islands of Corsica, Sicily and Sardinia. Its abundant and widespread populations in low and middle mountain streams of Corsica indicate that it is a Tyrrhenian faunal element which has been spread westwards into Eastern Pyrenees perhaps during the repeated waves of migration from the Paleocene (Montian) till the late Miocene. Mountain streams in Corsica represent an area of high endemism for several aquatic insect groups (Giudicelli 1975) and it is likely that some chironomid species have evolved there and subsequently spread to adjoining regions. Associated western Mediterranean faunal elements include, in the Plecoptera: Tyrrhenoleuctra zavatarii (Consiglio), Capnioneura petricola Giudicelli, Leuctra budtzi Peterson and Isoperla insularis (Morton); in the Trichoptera: Silonella aurata McLachlan, Silo rufescens McLachlan, Allogamus corsicus (Ris), Diplectrona magna Mosely and Polycentropus corsicus Mosely; in the Diptera: Liponeura insularis Giudicelli, Liponeura bischoffi (Edwards), Chaetocladius (Chaetocladius) algericus Moubayed, Cricotopus (Cricotopus) beckeri Hirvenoja, C. (C.) levantinus subsp. occidentalis Moubayed-Breil \& Ashe, Krenosmittia hispanica Wülker, Parametriocnemus valescurensis Moubayed \& Langton, Stempellinella reissi Casas \& Vilchez-Quero and Rheotanytarsus procerus.

Larvae of $R$. dactylophoreus are typically rheophilic and it occurs exclusively in running water habitats located in low to mid mountain streams, at an altitude of mostly 600-1200, rarely 1200-1400 $\mathrm{m}$ a.s.l. The melting of snow in late spring and early summer ensures a regular flow of water in the stream channels. The main sampled localities where larvae and pupae were collected consist of shady stretches of stream with small waterfalls and sandy to gravely substratum where bryocolous, hygropetric and madicolous habitats exist. Larval cases are built from bryophyte leaves mixed with sand grains and organic litter. Based on the material examined the emergence period of adults is June and July. Abundant populations are recorded exclusively in unregulated streams, whereas in regulated rivers larval and pupal populations are rare due to high variation in the water flow during spring and late summer. In some regulated streams, larval populations are recorded only in the upstream zone where favorable habitats provide better physical and hydrographic conditions.

Species encountered in the same localities consist of about 160 aquatic insects including about 70 chironomid species. Chironomid species found in the same streams are: Pentaneurella katterjokki Fittkau \& Murray, Boreoheptagyia legeri (Goetghebuer), Diamesa hamaticornis Kieffer, Bryophaenocladius nidorum (Edwards), Chaetocladius (Chaetocladius) perennis (Meigen), Corynoneura arctica Kieffer, C. lobata Edwards, Eukiefferiella fittkaui Lehmann, E. minor (Edwards), Heleniella serratosioi Ringe, Heterotrissocladius marcidus (Walker), Krenosmittia hispanica Wülker, Parametriocnemus stylatus (Spärck), P. valescurensis Moubayed \& Langton, Pseudorthocladius (Pseudorthocladius) berthelemyi Moubayed, Rheosmittia spinicornis (Brundin), Thienemannia gracilis Kieffer, Micropsectra junci (Meigen), M. nohedensis (Moubayed \& Langton), M. notescens (Walker), M. schrankelae Stur \& Ekrem, and Stempellinella reissi Casas \& Vilchez-Quero.

\section{ACKNOWLEDGMENTS}

The authors are grateful to the directors and staff responsible for the natural reserves in Corsica (Fango, Scandola, Restonica, Golo, Fium'orbu, Stabiacco, Biguglia, Gravona, Rizzanese, Porto, Pietracorbara) and the Eastern Pyrenees (Mantet, Eyne, Massane, Py, Prats-De-Mollo, Nohèdes, Carlit) for facilities and hospitality provided to J. M.-B. to collect material from springs, Pozzines, streams, lakes, estuaries and sea shores located in their protected wetland areas. Pupal exuviae of Rheotanytarsus procerus, from Morocco, have been kindly provided by Dr K. Kettani and we thank Martin Spies who provided us with additional taxonomic data from exuviae of $R$. procerus preserved in the Zoologische Staatssammlung (Munich) collections. We are indebted to Prof. F. Vaillant for valuable comments on the setation pattern of the eyes in Diptera and for suggesting the name for the new species. Improvements to the poster presented at the Trondheim Symposium were kindly made by Charlie Moubayed-Breil.

\section{REFERENCES}

Andersen T, Kyerematen RAK. 2001. South American Rheotanytarsus Thienemann et Bause, with the description of one new species (Diptera: Chironomidae). Norwegian Journal of Entomology 48: 269-274.

Burmeister EG, Reiss F. 2003. Rheotanytarsus reissi, eine zweite tuffbildende Wasserinsektenart (Diptera, Chironomidae). Lauterbornia 48: 77-88.

Chaudhuri PK, Datta T, Mazumdar A. 1994. Notes on the genus Rheotanytarsus Thienemann et Bause (Diptera, Chironomidae) with description of two new species from India. Russian Entomology Journal 3: 151-158.

Cloutier L, Harper PP. 1986. A new species of Rheotanytarsus from subarctic Quebec (Diptera: Chironomidae). Entomological News 97: 1-6.

Cranston PS. 1997. Revision of Australian Rheotanytarsus Thienemann et Bause (Diptera: Chironomidae), with emphasis on the immature stages. Invertebrate Taxonomy 11: 705-734. 
Fittkau EJ. 1960. Rheotanytarsus nigricauda n. sp. Chironomidenstudien VI. Abhandlungen herausgegeben vom Naturwissenschaftlichen Verein zu Bremen 35: 397-407.

Furon R. 1950. Les grandes lignes de la Paléogéographie de la Méditerranée (Tertiaire et Quaternaire). Vie et Milieu 1: 131162.

Furon R. 1972. Eléments de Paléoclimatologie. Vuibert, Paris, 210 pp, 24 Figures.

Giłka W. 2011. Ochotkowate - Chironomidae, plemię: Tanytarsini, postaci dorosłe, samce. Klucze do oznaczania owadów Polski. [Non-biting midges - Chironomidae, tribe Tanytarsini, adult males. Keys for the Identification of Polish Insects]. Nr 177 serii kluczy. Część XXVIII, Muchówki - Diptera, zeszyt 14b. Polskie Towarzystwo Entomologiczne. Biologica Silesiae, Wrocław, 95 str.

Giudicelli J. 1975. Analyse de l'endémisme dans la faune des eaux courantes de la Corse. Ecologia Mediterranea 1: 133-147.

Jeannel R. 1956. Les Psélaphides de l'Afrique du Nord. Essai de biogeographie berbère. Mémoires du Museum National d'Histoire Naturelle, Série A. Zoologie 14: 1-233.

Kyerematen RAK, Andersen T. 2002. Rheotanytarsus Thienemann et Bause (Diptera: Chironomidae) from Central America and Mexico. Studies on Neotropical Fauna and Environment 37: 23-51.

Kyerematen RAK, Sæther OA. 2000. A review of Afrotropical Rheotanytarsus Thienemann et Bause, 1913 (Diptera: Chironomidae). Tijdschrift voor Entomologie 143: 27-69.

Kyerematen RAK, Andersen T, Sæther OA. 2000 a. A review of Oriental Rheotanytarsus Thienemann \& Bause, with description of some new species (Insecta, Diptera, Chironomidae). Spixiana 23: 225-258.

Kyerematen RAK, Sæther OA, Andersen T. 2000 b. A review of the Rheotanytarsus pellucidus group (Diptera: Chironomidae). Pp 147-170. In: Hoffrichter O. (ed.). Late $20^{\text {th }}$ Century Research on Chironomidae: an anthology from the $13^{\text {th }}$ International Symposium on Chironomidae, Freiburg, 5-9 September 1997. Shaker Verlag, Aachen. 661pp.

Langton PH. 1991. A key to pupal exuviae of the West Palaearctic Chironomidae. Privately published Huntingdon, England. 386 pp.

Langton PH, Armitage PD. 1995. Rheotanytarsus rioensis (Diptera: Chironomidae), a new species of the pentapoda group from the Canary Islands. British Journal of Entomology and Natural History 8: 11-17.

Langton PH, Pinder LCV. 2007. Keys to the adult male Chironomidae of Britain and Ireland. Volume 1 (Pp: 1-239) and volume 2 (Pp: 1-168). Freshwater Biological Association, Scientific Publication, No. 64.

Langton PH, Visser H. 2003. Chironomidae exuviae. A key to pupal exuviae of the west Palaearctic region. Amsterdam: Biodiversity Center of ETI. CD-Rom.

Laville H, Langton PH. 2002. The lotic Chironomidae (Diptera) of Corsica (France). Annales de Limnologie 38(1): 53-64.

Lehmann J. 1970. Revision der europäischen Arten (Imagines $\widehat{\jmath} \widehat{\jmath}$ und Puppen $\hat{\delta} \hat{\sigma}$ der Gattung Rheotanytarsus Bause (Diptera, Chironomidae). Zoologischer Anzeiger 186: 344-378.

Lehmann J. 1981. Chironomidae (Diptera) aus Fließgewässern Zentralafrikas. Teil II: Die Region um Kisangani, Zentralzaire. Spixiana Supplement 5: 1-85.
Moubayed Z. 1990. Chironomids from running waters of Thailand: description of Rheotanytarsus thailandensis sp. n. and Tanytarsus thaicus sp. n. (Dipt., Chironomidae). Hydrobiologia 203: 29-33.

Moubayed J, Langton PH, Morello E. 2000. On some chironomid populations from permanent and temporary springs, streams and pools in France: distribution and biogeoraphical significance. In: Hoffrichter, O. (ed.). Late $20^{\text {th }}$ century research on Chironomidae: an anthology from the $13^{\text {th }}$ International Symposium on Chironomidae. Shaker Verlag, Aachen: 571-577.

Moubayed-Breil J. 2007. Non-biting midges from Continental France: new records, faunal and biogeographical outline (Diptera, Chironomidae. Ephemera 9(1): 17-32.

Shilova AI. 1976. Khironomidy Rybinskogo Vodokhrannilishcha. Izvestiya Academii Nauk SSSR 1976, 249 pp.

Sæther OA. 1980. Glossary of chironomid morphology terminology (Diptera: Chironomidae. Entomologica Scandinavica Supplement 14: 1-51.

Sæther OA, Kyerematen RAK. 2001. Towards phylogeny and zoogeography of the genus Rheotanytarsus Thienemann et Bause, 1913 (Diptera: Chironomidae). Tijdschrift voor Entomologie 144: 73-117.

Sæther OA, Spies M. 2011. Chironomidae. In: Fauna Europaea Service (ed.). Fauna Europaea, internet database at http://www. faunaeur.org [visited April 2011].

Wang X, Guo Y. 2004. A review of the genus Rheotanytarsus Thienemann \& Bause from China (Diptera: Chironomidae: Tanytarsini). Zootaxa 650: 1-19.

Wang X, Zheng L. 1993. [Genus Rheotanytarsus Thienemann and Bause (Diptera: Chironomidae)]. Acta Scientiarum Naturalium Universitatis Nankainensis 1993 (1): 89-93. [In Chinese] 